\title{
From Critical Thinking to Artful Communication: Inspirations from Dewey's Theory of Communication
}

\author{
Jessica Ching-Sze Wang \\ National Chiayi University, Taiwan
}

\begin{abstract}
The idea of Philosophy for Children (P4C) initiated by Matthew Lipman aims to foster critical and creative thinking in children through the pedagogy of a community of inquiry. In his formulation of P4C, Lipman emphasizes the role of logical reasoning in thinking and assumes a mutually reinforcing relationship between critical and creative thinking. In this paper, I present an example of a real classroom dialogue which illustrates the inherent tension between logical and creative thinking, as well as the need to go beyond critical thinking. I then proceed to argue for the importance of communication in creating and sustaining a genuine community of inquiry. In conclusion, I suggest that John Dewey's view of communication as essentially transformative, aesthetic, educative, and moral can be made the basis for envisioning an alternative focus of P4C-namely, the ideal of artful communication, which has far-reaching implications for realizing the democratic idea of "community" in a community of inquiry.
\end{abstract}

Keywords: Matthew Lipman, John Dewey, philosophy for children, critical thinking, communication

\section{Introduction}

The idea of philosophy for children (P4C) was initiated in the1970s by the American scholar Matthew Lipman and has since been promulgated in many countries around the world. According to Lipman (1991), P4C aims to foster "critical and creative thinking" in children through inquiry and dialogue. While scholars have different conceptions as to what critical thinking entails and how to enlist critical thinking skills in dialogue, they all seem to agree that the training of critical thinking skills and the search for truth and meaning should be the guiding principles for a $\mathrm{P} 4 \mathrm{C}$ community of inquiry.

In Lipman's model, critical thinking is closely associated with questioning, analyzing, judging, and, most importantly, logical reasoning. In this paper, I problematize the idea that logical reasoning should be taken as the primary guiding principle for engaging children in thinking and for facilitating communication in dialogue. To illustrate the point about the limitation of logic in facilitating philosophical dialogue, I present an example of a real classroom dialogue which illustrates the inherent tension between logical thinking and creative thinking, as well as the need to go beyond critical thinking. I then proceed to argue for the importance of communication in creating and sustaining a genuine community of inquiry. In conclusion, I suggest that John Dewey's view of communication as essentially transformative, aesthetic, educative, and moral can be made the basis for

Jessica Ching-Sze Wang, Ph.D., associate professor, Department of Education, National Chiayi University, Taiwan; main research field: Philosophy of Education and Philosophy for Children.

Acknowledgements: I would like to express appreciation to Taiwan's Ministry of Science and Technology for supporting this research (103-2410-H-415-033). 
envisioning an alternative focus of P4C, namely, the idea of artful communication.

\section{Critical Thinking as the Primary Goal of P4C}

The Lipman model of P4C focuses on promoting a type of higher-order thinking which encompasses critical and creative thinking and amounts to a form of judgment. According to Lipman, "critical thinking involves reasoning and critical judgment; creative thinking involves craft, artistry, and creative judgment.” In other words, to think is to judge. To judge is "to judge relationships, either by discovering relationships or by inventing them;" it denotes a process of "finding or making connections and disjunctions" (Lipman 1991, 16-17, emphasis mine). Accordingly, thinking as judgment centers on intellectual activities such as doubting, questioning, comparing, and contrasting.

In Thinking in Education, Lipman (1991) proposes as a pedagogical method for P4C a "community of inquiry" in which students are encouraged to learn collaboratively through active listening to one another, building on each other's ideas and sharing their views. They are also expected to "assist each other in drawing inferences from what has been said, and seek to identify one another's assumptions” (Lipman 1991, 15). Participants in a community of inquiry invariably bring their own experiences to the discussion, but are encouraged to explore disagreements by paying attention to their own thinking and that of others. Once established, a community of inquiry generates its own agenda and participants are encouraged to "follow the inquiry where it leads rather than being penned in by the boundary lines of exiting disciplines" (Lipman 1991, 15). Lipman argues that a community of inquiry provides an effective pedagogy for engaging students in philosophical dialogue and enhancing their critical thinking skills.

Philosophical dialogue that aims to engage children in critical thinking is not mere conversation. It is self-correcting, sensitive to context, and it relies on criteria (Lipman 1991). The underlying purpose of dialogue in inquiry is to "progress toward truth" (Gardner 1995, 38). Such dialogue is neither centered on, nor controlled by, teacher or student, but rather by the demands of truth. The search for truth takes children one level beyond the average classroom dialogue. It is a dialogue "disciplined by logic," where participants "must reason in order to follow what is going on” (Lipman 1991, 236). As Lipman elaborates:

When the classroom has been converted into a community of inquiry, the moves that are made in order to follow the argument where it leads are logical moves. As communities of inquiry proceeds with its deliberations, every move engenders some new requiredness. The discovery of a piece of evidence throws light on the nature of the further evidence that is now needed. The disclosure of a claim makes it necessary to discover the reasons for that claim. The making of an inference compels the participants to explore what was being assumed or taken for granted that led to the selection of that particular inference. A contention that several things are different demands that the question be raised of how they are to be distinguished. Each move sets up a train of countering and supporting moves. As subsidiary issues are settled, the community of inquiry's sense of direction is confirmed and clarified, and the inquiry proceeds with renewed rigor. (Lipman 1991, 236)

The P4C community of inquiry "tries to conform to logic... and move forward indirectly like a boat tacking into the wind, but in the process its progress comes to resemble that of thinking itself” (Lipman 1991, 15-16).

Although Lipman also pays attention to creative thinking and caring thinking in his writings (Lipman 1991; 2003), the major paradigm of critical thinking in P4C is analytical, logical reasoning. The required thinking skills include giving good reasons, making good distinctions, making valid inferences, hypothesizing, asking good questions, using and recognizing criteria, calling for evidence, seeking clarification, offering alternative 
points of view, building logically on the contributions of others, posing counter examples, asking for reasons, testing, and so on (Lipman, Sharp, and Oscanyan 1980; Sharp 1993). "One of the values of learning formal logic," Lipman contends, is that "it requires the learning of rules for the standardization of everyday language so that the complexities of ordinary discourse can be reduced to the simplicities of logical language" (Lipman 1991, 46). Although Lipman acknowledges that "this does considerable damage to meaning," he maintains that this is a worthwhile sacrifice, for "it demonstrates to students that natural language has an underlying musculature that makes possible such pushing and pulling as are involved in inference, casual expressions, and the like, and that natural language can be translated into this rudimentary but powerful logical language" (Lipman 2003, 45-46).

Lipman is also concerned with creative thinking, but he posits a mutually reinforcing relationship between critical thinking and creative thinking, asserting that, "there is no critical thinking without a modicum of creative judgment," and that "there is no creative thinking without a modicum of critical judgment" (Lipman 2003, 21). According to Lipman, both critical and creative thinking aim at "judgment;" the former is concerned with "truth," while the latter is concerned with "meaning;" the former is "governed by singular criteria," while the latter is "sensitive to contrasting criteria;" the former is "self-correcting," while the latter is "self-transcending;" the former is "sensitive to context," while the latter is "governed by context" (Lipman 1991, 193). However, an important question goes unasked: In actual dialogue, can one always expect a harmonious interplay between these two forms of thinking? Might there be an inherent tension? In mainstream P4C theory and practice, critical thinking is recognized as a primal goal to pursue and is thought to be trainable through systematic practice. Creative thinking, on the other hand, does not receive as much attention as critical thinking in P4C research. Creative thinking seems to be taken for granted as a natural accompaniment of dialogical practice. This paper is concerned with the potential tension between critical and creative thinking, particularly when critical thinking is narrowly construed as logical reasoning.

Let us look at an example of how logical reasoning serves to guide a P4C classroom discussion and explore how it may trump more creative ways of searching for meaning.

\section{Example of a Community of Inquiry "Disciplined by Logic"}

The following dialogue is taken from Ronald Reeds' (1980) article "Fifth Graders Discuss Evidence, Knowledge and Truth.” At the time of the discussion, this class of fifth graders had been meeting for five weeks, twice a week, and they had already read up to Chapter Seven of Harry Stottlemeier's Discovery, the first P4C novel written by Lipman. In this short segment of the transcript, the students try to clarify what it means to prove something. Reed (Ron in the transcript) is the teacher and his students are Holly, Beth, and Mitch.

Ron: Can I prove to you something that is false? Can I prove to you $2+2=5$ ?

Holly: You can prove it, but I wouldn't believe it because I know it's not true.

Beth: But then you wouldn't be proving it. I mean I'd know it was false and you'd know it was false and it wouldn't be a proof.

Holly: So if we both knew it was false then it would not be proved.

Mitch: What about if you were proving it to 10 people and make believe some people knew it was true and some people knew it was false. Then could you prove it?

Beth: If some people knew it was true...

Ron: Isn't that a different case? Weren't we talking about it being false?

Mitch: Right. It is false for some people, but it is true for other people. 
Ron: Remember the discussion we had on contradiction. A sentence can't be both true and false at the same time. $2+2=4$ is either true or false. Can't be both, right?

Mitch: Right.

Ron: Right. You did agree before. You can change your mind if you want.

Mitch: O.K. What about if... If... What Beth said was something... Beth said something would not be a proof because I know it was false and you know it was false.

Ron: Beth is saying...

Beth: ... that you can't prove something that everybody knows is false. Or really you can't prove something that is false.

(Pause)

Ron: That's a pretty big change, an addition you made there? No?

Beth: What.

Ron: Well first you said you can't prove something that everybody knows is false. Then you said you can't prove something that simply is false. Whether people know it's true or false doesn't seem to matter them.

Beth: O.K.

(Pause)

Ron: Well, what do you want to say now?

Beth: The second one. It doesn't matter whether anybody knows or not.

Ron: O.K. Anybody else has anything to say.

(Pause)

Ron: I bet there's a lot more we could say about proof. But maybe we have enough to begin comparing things. If you prove something, what you prove must be true. Right. (Reed 1980, 69, emphasis mine)

In this class, Ron and his students were discussing logical concepts, including "proof," "evidence," "knowledge," and "truth.” At the beginning, Ron proposed the question of whether one can prove something that is false, for instance, " $2+2=5$." The initial response from Holly is "Yes," even though she added that it wouldn't be believed. This then leads to the next point about the distinction between proving something and believing something, with the underlying assumption that the concept of "proving" requires "someone to believe it to be true." As they exchanged their views, Holly and Beth came to see that something that is known by people as false cannot be proved at all. That is to say, people's “knowledge” (in this case Holly's and Beth's knowledge) of whether something is true or false is taken to constitute a criterion for judging whether the thing can be proved.

At this juncture, Mitch raised an interesting question: What if we come to a situation in which some people believe and others disbelieve? Would that change the answer to the question about proof? This is, indeed, an important point to clarify, one that builds on prior discussion but throws into question the earlier agreement. When Beth tried to respond to Mitch, she was interrupted by Ron, the teacher, who seems to suggest that Beth's reply, though unfinished, might be irrelevant. It was a bit unclear what Ron intended to say. Despite the interruption, Mitch managed to follow the original line of argument, reinstating the unresolved scenario about someone knowing something to be true and others knowing it to be false.

To make himself better understood, Ron offered a specific reminder- "Remember the discussion we had on contradiction. A sentence cannot be both true and false at the same time. $2+2=4$ is either true or false. Can't be both, right?” In fact, Ron was pointing out the logical contradiction in the statement about something being believed to be true (by some people) and to be not true (by others). If we follow Ron's logic, the student's statement can be reduced to suggest the following: There is a thing, A; A is believed by $\mathrm{X}$ to be true and is believed by Y to be false; A is believed to be both true and not true; therefore, $\mathrm{A}$ is both true and not true at the same time. Clearly, the reformulated statement is logically false, yet empirically true. 
It is not clear whether Mitch grasped the intricate logical reasoning behind Ron's reminder. Mitch responded with a quick "Right," but continued to pursue Beth's earlier point, which was cut short by Ron ("What Beth said was something..."). Then Beth tried to speak for herself and made a big leap in her thinking. She said, "You can't prove something that everybody knows is false. Or really you can't prove something that is false.” Ron hastened to assure the logical significance of Beth's statement and prompted her to clarify her stance.

Beth chose the correct logical answer: "It doesn't matter whether anybody knows or not.” In other words, she came to see that something is proven to be true because it is true, not because someone believes it to be true. Beth's new understanding is soon followed by Ron's concluding remark: "If you prove something, what you prove must be true.” This part of the dialogue ended at this point, when a logically sound conclusion had been reached, namely, what one claims to prove must be true in itself.

Then the teacher moves on to discuss the difference between evidence and proof.

According to Reed $(1980,68)$, “the classroom discussion was very energetic.” The students were given the opportunity to freely exchange their views; they also actively listened to each other and built on each other's arguments. Most importantly, this dialogue was characterized by the use of logical rules to guide reasoning. Although logical reasoning serves to propel discussion, it can also serve to terminate discussion. In the dialogue, we see that once a logically sound argument has been presented ("if you prove something, what you prove must be true," regardless of whether someone believes it to be true or false), the discussion proceeds to the next round. Let us imagine what the children might say, if the teacher leaves the floor open for further exploration of meaning. They might say something like this: How do we know what is true? Can we ever know what is true? Why do we want to prove it, if what I say or what you say about it does not matter? If truths are proven to be true because they are true, who is to prove them in the first place? Can truths prove themselves? Or should truths be proven by people? If the truth is to be proved, doesn't it require a person, the one proving it, to prove it and to know it to be true?

These, of course, are my own speculations, but these speculations make room for more divergent, imaginative thinking and for more questions about meaning, even though they would barely change the logic-proof answer that "if you prove something, what you prove must be true." This model of a community of inquiry — with its search for the truth and its emphasis on logical certitude—may suffer from a lack of original, novel, and unconventional thinking.

I do not disagree that objective standards such as logical rules help to orient directions for thinking. However, when logic becomes a monolithic and totalizing force of authority in dialogue, it inevitably closes off other possibilities of thinking, such as searching for meaning. In addition, logic-centered discussion tends to focus merely on language, i.e., propositional statements, and neglects other symbolic signs in interpersonal dialogue, including bodily senses, emotion, empathy, and other aesthetic sensibilities and feelings-all of which can contribute to the communication of ideas and the interpretation of meanings.

\section{Thinking beyond Critical Thinking: Regaining Communication and Community}

In the mainstream model of P4C, the idea of "criticality" is largely equated with that of judgment, or as Papastephanou and Angeli (2007) point out, that of "evaluation," as in evaluating the reasons for arguments. According to Vansieleghem, this model is based on a "methodological ideal of procedural rationality" and unfortunately overlooks the natural tendency of children "not to question or to doubt, but to wonder about the 
meaning of something” (Vansieleghem 2005, 30). Although the participants in a community of inquiry are free to express their thoughts, their freedom is bound by the confines of logic. Vansieleghem (2005) uses Hanah Arednt's notion of freedom to argue for more creative ways of encountering the world anew:

According to Arendt, freedom resides in natality, and the responsibility to respond to the appearance of something or someone new is what she has called "thinking." This thinking cannot be acquired in conventional ways; it is not a capacity for reflexive problem-solving, or a skill or a strategy; rather it is a search for meaning. (Vansieleghem 2005, 30)

Moreover, "freedom has nothing to do with choices; it is rather to do with the possibility of creating something that did not exist before, neither as thing or image, nor as knowledge itself. It is the possibility of the impossible" (Vansieleghem 2005, 25). With a logical eye, one cannot see the "possibility of the impossible" because it does not "follow" from any given premise.

Contemporary feminist critiques of mainstream critical thinking theories also challenge the inherent problems with exclusive emphasis on logic and rationality. Thayer-Bacon (1993), for example, proposes to replace the model of rational, critical thinking with constructive, caring thinking. She says: "To be a caring thinker, one needs a high tolerance for internal contradiction and ambiguity, and one needs to learn to live with conflict. She has to abandon the either/or distinctions of traditional thinking and search for a unique and authentic voice" (Thayer-Bacon 1993, 335).

Thayer-Bacon also argues against the long-standing separation between the knowing self and the known object, and seeks to legitimize and authenticate what she calls "the subjective voice:" "Subjective voice is not selfish, self-centered voice. It is just what each of us contributes to any knowing situation. By this account, we develop our thinking skills as we develop our communication skills, and our social skills, by being in relations with others” (Thayer-Bacon 1993, 337). Thayer-Bacon contends that the feminist epistemological paradigm takes knowledge to be fluid and dynamic, depending on how people interact and share insights.

As far as critical rationality is concerned, Burbules (1993) also proposes to use reasonableness to replace Reason with a capital R. While rationality sets up a system of rules with which everyone has to comply, reasonableness is sensitive to the demands of people and context. Reason cannot be devoid from practice and should be "a practice growing out of communicative interactions in which the full play of human thought, feeling and motivation operates” (Burbules 1993, 85-86).

The focus on logical reasoning can lead to a neglect of "the full play" of human interaction; it can also jeopardize the idea of community. The idea can be unduly relegated to a subordinate role because it only functions to assist participants in the process of inquiry. It is easy to take the idea of community for granted and to assume that as long as a group of people keeps practicing philosophical dialogue, the community will be solid.

In the view of Thomas Jackson (2001), a very experienced P4C practitioner and philosopher in Hawaii, a mere group of people can hardly qualify as a community of inquirers when it is not "intellectually safe" to talk among participants and when a few people, the teacher included, dominate discussion. To form an intellectually safe community of inquiry, Jackson asserts that listening is more important than questioning or logical reasoning:

A salient feature of dialogue is not questioning (let alone, cross-examination) but listening. Dialogue's first interest is not to counter, debate, disagree, lead, or expose, but to genuinely and simply listen. This quality of listening requires setting one's own thoughts in order to be truly open to what the other is saying. This is especially important because the "other" in 
this case will most often be a child, and gentleness must be foremost in one's mind if one hopes to be privileged with an authentic response from a child. (Jackson 2001, 459)

The following reflections from Thomas Yos, another P4C Hawaii researcher and practitioner, are also revealing:

I still whole-heartedly believe in the power of philosophical inquiry. But I've also come to realize that there is a very important something else that makes the "community of inquiry" approach so valuable. What's important about the idea of community of inquiry, especially in this day and age, isn't just the inquiry part; it's the community part... It is so important because it purposefully cultivates what many of today's schools are unwisely leaving too far on the fringe: the loving, caring, fun-filled human relationships which are at the core of human flourishing. (Yos 2011, 52)

In short, the emphasis on logic alone is insufficient, if not inherently inadequate, to create "the loving, caring, fun-filled relationships” that help to sustain a genuine community of inquiry.

\section{From Critical Thinking to Artful Communication: Inspirations from John Dewey’s Theory of Communication}

In their essays on critical thinking, Thayer-Bacon and Burbules respectively point to the importance of communication in dialogical discussion and in the training of thinking. Here I would like to argue that John Dewey's notion of communication can shed new light on how to enhance communication in a P4C community of inquiry, thus transforming our focus from critical thinking to artful communication.

The notion of communication occupies a privileged place in his overall philosophy of education. In Experience and Nature (1925), Dewey opens Chapter Five by stating that "Of all affairs, communication is the most wonderful” (Dewey 1925, 132). This "wonderful” nature of communication captivated Dewey so much that in that book, Dewey seems less interested in talking about either experience or nature, than in working out "a theory of how communication is possible and why we need it" (Sleeper 1986, 117). Biesta (2004) contends that Dewey actually "developed his theory of education as a theory of communication” and sought to establish clear links between communication and reflective thinking; further, he saw communication as "a process of social coordination and cooperation," a process that "not only effectuates common understanding and a common, shared world but... is also the origin of reflection and reflective consciousness" (27).

What is so wonderful about communication? In Democracy and Education (1916), Dewey declares that “all communication is educative” (Dewey 1916, 8). Communication leads to a transformation of experience. In the same work, Dewey also states, “To be a recipient of a communication is to have an enlarged and changed experience. One who shares in what another has thought and felt and in so far, meagerly or amply, has his own attitude modified” (Dewey 1916, 8). In other words, one learns by sharing in another person's experience. When one truly taps into the experience of another, one vicariously enters into her world for what it is. Such vicarious experience helps us learn about the richness and variedness of human thoughts and feelings, stories and contexts. Through the process of sharing, one is invited to look into a kaleidoscope of life that presents before our eyes the fullness of the human condition.

Communication thus understood is indeed educative; nonetheless, it is not easily attainable. Dewey never assumed it to be otherwise. Certain conditions or requirements have to be met for communication to be a truly genuine and educative experience for all who participate in this process. To start off, one should never assume that to communicate means simply to convey intelligible sound signals into the ears of others. The way we communicate our experience to others determines how others receive it. The way others respond to our 
experience will in turn influence how this communicative process thereafter unfolds. In this process of give and take, one will find one's attitude toward the experience changed. Dewey urged readers to "try the experiment of communicating, with fullness and accuracy, some experience to another, especially if it be somewhat complicated...” As a result, “you will find your own attitude toward your experience changing” (Dewey 1916, 9).

Here Dewey's insights about communication merit careful attention. He believed that the very process of communication creates opportunities for transformation, and hence growth, for both participating agents. Let us consider this point from the perspective of the giving agent. As Dewey observed, to communicate an experience to another, one has to first formulate it. "To formulate requires getting outside of it; seeing it as another would see it; considering what points of contact it has with the life of another so that it may be got into such form that he can appreciate its meaning” (Dewey 1916, 9). Such "seeing," such mental awareness, on the part of the giving agent, "stimulates and enriches imagination" (Dewey 1916, 9). It urges the agent to step out of a habitual mode of thinking and enter into a wider dimension that potentially connects with the life of another. When one is thus freed from fixed, routine ways of thinking and responding, one experiences the world anew, however, small or inconsequential, this newness may appear. In fact, the giving agent experiences what Dewey means by education as growth—“a continuous process of reorganizing and reconstructing of experiences" (Dewey 1916, 9).

Dewey's conception of the requirements for genuine communication is intellectually challenging, for the very process itself “creates responsibility for accuracy and vividness of statement and thought” (Dewey 1916, 9). In my view, this responsibility is shared by both parties in communication: the speaker and the listener. Firstly, the speaker should try to make her ideas as accurate, vivid, and comprehensible as possible; secondly, she needs to reformulate the experience in her mind and present it in a listener-friendly fashion, that is, from the perspective of how the listener may best receive it. However, this principle of intellectual responsibility also applies to the listener as well. The listener has to monitor the process of communication with equal attentiveness, care, and discretion: She has to think about whether the information being presented is intelligible, whether she can grasp its meanings, and whether she can appreciate them properly and responsively. The listener needs to display an epistemic virtue of caring for truth: Namely, she has to examine whether the ideas or meanings emerging in her mind actually cohere with what the speaker intends to express. When their meanings cohere, mutual understanding takes place: One understands and the other feels understood.

In Experience and Nature (1925), Dewey explains how communication works. He supposes two agents, A and $\mathrm{B}$, in a communicative process in which A proposes a request to B. “The characteristic thing about B's understanding of A's movement and sounds is that he responds to the thing from the standpoint of A. He perceives the thing as it may function in A's experience, instead of just ego-centrically” (Dewey 1925, 141). Similarly, Dewey says, "A in making the request conceives the thing not only in its direct relationship to himself, but as a thing capable of being grasped and handled by B. He sees the thing as it may function in B's experience" (Dewey 1925, 141). Therefore, Dewey concludes: "Such is the essence and import of communication, signs, and meaning. Something is literally made common in at least two different centers of behavior. To understand is to anticipate together; it is to make a cross-reference which, when acted upon, brings about a partaking in a common, inclusive, undertaking” (Dewey 1925, 141). What stands out in this seemly simplistic statement is the underlying assumption that "egocentric" thinking impedes communication.

For Dewey, communication requires mindfulness. Such "communicative mindfulness," to use Stroud's (2010-2011, 57) term, is intellectually challenging and stimulating, and also rich with moral implications. The 
first moral obstacle to overcome is egocentrism, namely, thinking and living in one's own world and failing to anticipate and understand that others may experience the world differently than I do. Dewey's depiction of communicative mindfulness is also deeply moral in that it constitutes an act of care. The speaker cares if the listener can understand and appreciate the meaning of her experience; the listener cares if she can fully and intelligently understand the speaker's experience. Taken together, this communicative mindfulness and care is "wonderful" for Dewey, because it contributes to an enlightened understanding of one's self and the self of another. This is accomplished by engaging in a mindful communication practice that allows one the chance to examine one's ideas and experiences in a complex web of potential meanings, meanings that are not yet realized by oneself, and meanings that are continually extended by the contribution of others. As Dewey puts it in Democracy and Education (1916), "A man really living alone... would have little or no occasion to reflect upon his past experience to extract its net meaning” (Dewey 1916, 9). When we thus engage in interpersonal communication, through the mirror of others, we come to a deeper understanding of who we are.

Dewey's normative notion of communicative mindfulness is aesthetic in nature. It challenges us to rethink whether our everyday routine conversations and interactions with others count as "communication." After all, we tend to communicate at the surface level. We talk, but do not talk deeply enough for others to understand and appreciate what we say. We listen, but do not listen deeply enough to understand what others intend to say. We are often non-engaged or distracted in our immediate communicative situations. The practice of mindfulness helps us stay attentive and focused on the present moment and to extract and experience the aesthetic element in each communicative situation. As Dewey asserts, "all communication is like art" (Dewey 1916, 9). Crick calls this mindful process a "transformative art” (Crick 2005, 8), for it functions to transform the heart and mind of those who participate in it.

For Dewey, the connection between communication and democracy is crucial. He ends The Public and Its Problems (1927) by stating that "Democracy will have its consummation when free social inquiry is indissolubly wedded to the art of full and moving communication” (Dewey 1927, 350). The claim that P4C can contribute to democracy has been well established by such practitioners as Sharp (1993). However, the question of whether P4C can be seen as a continuation of Dewey's democratic project (Daniel, Schleifer, and Lebouis 1992) is a different matter. Although the idea of P4C is often linked to the inspiration of Dewey (Lipman 2004), I think it needs to gain more insights from Dewey's notion of communication if it is indeed concerned with promoting democracy in the Deweyan sense.

\section{The Roles of Sympathy and Imagination in Artful Communication}

Having elaborated on what Dewey means by communication, about its educative, aesthetic, transformative, and moral value, let us explore the substantive elements in this communicative process. In Dewey's mind, communication has less to do with analytical, logical reasoning, and more to do with sympathy and imagination. The connection between sympathy and communication in Dewey's theory is revealing, particularly when we compare his comments about sympathy in his early works with his explication about communication in his later works. In Psychology (1887), Dewey writes:

Sympathy, in short, is the reproduction of the experience of another, accompanied by the recognition of the fact that it is his experience... The conditions of sympathetic feelings are, therefore, first, ability to apprehend, consciously or unconsciously, the feelings of others, and to reproduce them in our minds: and, secondly, the ability to forget self, and remember that these feelings, although our own feelings, are, after all, the experiences of someone else. (Dewey 1887, 285) 
Both sympathy and communication require the ability to "forget self" or to forgo "thinking egocentrically.”

Moreover, Dewey compares the process of communication to that of translation, stating:

The first step in this communication is changing it from a psychical fact to a physical fact. It must be expressed through non-conscious media - the appearance of the face, or the use of sounds. The next step in the communication is for some other individual to translate this expression, or these sounds, into his own consciousness. He must make them part of himself before he knows what they are. One individual never knows directly what is in the self of another; he knows it only so far as he is able to reproduce it in his own self. (Dewey 1887,9 )

Communication (both verbal and physical) aims at understanding. To communicate is to translate other people's experience and to reproduce it in one's own consciousness.

Imagination, not logic, plays an essential role in this communicative process of translation. Imagination means "penetration into the hidden meaning of things-meaning not visible to perception or memory, nor reflectively attained by the processes of thinking” (Dewey 1887, 171). Dewey argues that analytical, reflective thinking cannot replace the role of imagination in communication aiming at understanding. How does imagination actually work then? As Dewey states:

It makes its object new by setting it in a new light. It separates and combines, indeed; but its separations and combinations are not the result of mechanical processes, nor of the feeling of the moment. They are filled with a direct and spontaneous sense of the relative values of detail in reference to the whole. All is left out that does not aid in developing the image of this whole; all is put in that will round out the meaning of the details and elevate them into universal and permanent significance. (Dewey 1887, 171)

To communicate and to understand something fully is to grasp the idea holistically in one's consciousness - to see it as a whole, not as parts or fragments. Analytical, logical thinking attempts to understand something by breaking it into parts; imaginative thinking attempts to understand something by bringing all the fragmented parts into a whole-thus perceiving it in a qualitatively new light. Both are intellectually rigorous and conducive to the search for truths.

My discussion of the roles of sympathy and imagination in the Deweyan conception of communication may seem rather sketchy. However, my purpose is to point out these neglected aspects in our conception of a community of inquiry and to redirect the focus of P4C from critical thinking to creative and imaginative thinking, and to sympathetic understanding. In my view, the idea of "community" in our conception of a community of inquiry deserves more attention, both scholarly and pragmatic. Drawing from Dewey's insights on communication is simply a beginning step toward that task.

Let me end this paper with a question and a plea. My understanding of a community of inquiry is that it is not merely about dealing with propositional statements in the abstract, but consists of real people and addresses the questions they encounter in real-life contexts. If the participants in a community of inquiry do not strive to understand each other (the lived, subjective worlds of each other's experiences) through effective and artful communication, how can they aspire to have an objective understanding of the truths of the external world? If the search for objective truths in the world is a paramount concern of philosophers, let the search begin locally and democratically at home-in the minds and hearts of those sitting next to us in a community circle of inquiry—so that we may all learn, grow, and flourish in that process. 


\section{Works Cited}

Biesta, Gert. “'Of All Affairs, Communication Is the Most Wonderful’: The Communicative Turn in Dewey’s Democracy and Education.” Ed. David Hanson. John Dewey and Our Educational Prospect. New York: SUNY Press, 2004. 23-37.

Burbules, Nicholas. "Rethinking Rationality: On Learning to Be Reasonable.” Ed. Audrey Thompson. Philosophy of Education. Urbana: Philosophy of Education of Society, 1993. 340-9.

Crick, Nathan. John Dewey on the Art of Communication (Unpublished doctoral dissertation). Pittsburgh: University of Pittsburgh, 2005.

Daniel, Marie-France, Schleifer Michael, and Lebouis Pierre. “Philosophy for Children: The Continuation of Dewey’s Democratic Project. Analytic Teaching 13 (1992): 3-12.

Dewey, John. Psychology. Ed. Larry Hickman. The Early Works of John Dewey, Vol. 2. The Collected Works of John Dewey, 1882-1953: The Electronic Edition. Charlottesville: InteLex, 1996.

---. Democracy and Education. Ed. Larry Hickman. The Middle Works of John Dewey, Vol. 9. The Collected Works of John Dewey, 1882-1953: The Electronic Edition. Charlottesville: InteLex, 1996.

---. The Public and Its Problems. Ed. Larry Hickman. The Later Works of John Dewey, Vol. 2. The Collected Works of John Dewey, 1882-1953: The Electronic Edition. Charlottesville: InteLex, 1996.

---. Experience and Nature. Ed. Larry Hickman. The Later Works of John Dewey, Vol. 1. The Collected Works of John Dewey, 1882-1953: The Electronic Edition. Charlottesville: InteLex, 1996.

Gardner, Susan. “Inquiry Is No Mere Conversation (or Discussion or Dialogue): Facilitation Is Hard Work!” Critical and Creative Thinking: The Australasian Journal of Philosophy for Children 3 (1995): 38-49.

Jackson, Thomas. “The Art and Craft of ‘Gently Socratic’ Inquiry.” Ed. Arthur L. Costa. Developing Minds: A Resource Book for Teaching Thinking. 3rd ed. Alexandria: Association for Supervision and Curriculum Development, 2001. 459-65.

Lipman, Matthew, Sharp Ann Margaret, and Oscanyan, F. S. Philosophy in the Classroom. Philadelphia: Temple University Press, 1980.

Lipman, Matthew. Thinking in Education. New York: Cambridge University Press, 1991.

---. Thinking in Education. 2nd ed. New York: Cambridge University Press, 2003.

---. "Philosophy for Children's Debt to Dewey.” Critical and Creative Thinking 12 (2004): 1-8.

Reed, Ronald. "Fifth-Graders Discuss Evidence, Knowledge and Truth.” Thinking: The Journal of Philosophy for Children 2.1 (1980): 68-71.

Stroud, Scott. "Toward a Deweyan Theory of Communicative Mindfulness.” Imagination, Cognition and Personality 30.1 (2010-2011): 57-75.

Sharp, Ann Margaret. “The Community of Inquiry: Education for Democracy.” Ed. M. Lipman. Thinking Children and Education. Dubuque: Kendall/Hunt Publishing Company, 1993. 337-45.

Sleeper, R. W. The Necessity of Pragmatism: John Dewey’s Conception of Philosophy. New Haven: Yale University Press, 1986.

Thayer-Bacon, Barbara. “Caring and Its Relationship to Critical Thinking.” Educational Theory 43 (1993): 323-40.

Papastephanou, Marianna and Angeli Charoula. “Critical Thinking beyond Skill.” Educational Philosophy and Theory 39 (2007): 604-20.

Vansieleghem, Nancy. "Philosophy for Children as the Wind of Thinking.” Journal of Philosophy of Education 39.1 (2005): 21-35.

Yos, Toby. "Raising the Bar: Love, the Community of Inquiry, and the Flourishing Life.” Educational Perspectives 44.1-44.2 (2011): 52-57. 